\title{
A Preliminary Preparation of Endophytic Bacteria CE3 Wettable Powder for Biological Control of Postharvest Diseases
}

\author{
Hua CHENG ${ }^{1,2, a}$, Linling $\mathrm{LI}^{1,2, \mathrm{~b}}$, Juan $\mathrm{HUA}^{1,2}$, Honghui YUAN ${ }^{1,2}$, Shuiyuan CHENG ${ }^{1,2 *}$ \\ ${ }^{1}$ Economic Forest Germplasm Improvement and Comprehensive Utilization of Resources of Hubei Key Laboratory, Huanggang Normal University, Huanggang \\ 434025, Hubei,China; chenghua1437@126.com; lilinling1437@126.com; harry1437@126.com;yuanhonghui604@yahoo.com.cn \\ ${ }^{2}$ College of Biology and Pharmaceutical Engineering, Wuhan Polytechnic University, Wuhan 430023, Hubei, China; \\ s_y_cheng@sina.com (*correspondingauthor) \\ ab the authors contributed equally to this study
}

\begin{abstract}
Recently, there has been an increasing interest among researchers in using combinations of biological control agents to exploit potential synergistic effects among them. In the present study, there were investigated commercially acceptable formulations of Bacillus cereus CE3 wetting powder with long storage life and retained efficacy to control chestnut and other fruit rot caused by Endothia parasitica (Murr) and Fusarium solani. The study sought to develop a new B. cereus formulation that would be more effective and better suited to the conditions of field application. By a series of experiments, the formulation was confirmed as follows: $60 \% \mathrm{~B}$. cereus freeze-dried powder, $28.9 \%$ diatomite as carrier, $4 \%$ sodium lignin sulfonate as disperser, $6 \%$ alkyl naphthalene sulfonate as wetting agent, $1 \% \mathrm{~K}_{2} \mathrm{HPO}_{4}$ as stabilizer, $0.1 \% \beta$-cyclodextrin as ultraviolet protectant. The controlling experiments showed that the diluted 100 times of $60 \%$ B. cereus wetting powder had $79.47 \%$ corrosion rate to chestnut pathogens; and this result is comparable to the diluted 1,000 times of $70 \%$ thiophanatemethyl. Safety evaluation results showed that rats acute oral lethal dose $50 \%$ was $5,000.35$, therefore application of $B$. cereus wettable powder could not cause a person or animal poisoning. This work illustrated that $60 \% \mathrm{~B}$. cereus wetting powder had commercial potential; however, to apply this formulation as a biological pesticide in the field, masses production processes need to be further studied.
\end{abstract}

Keywords: biocontrol, chestnut, endophyte, pathogenic bacteria, stabilizer, UV protective agent

\section{Introduction}

In recent years, the agricultural industry has experienced strong market and technological competition among the leading producing countries. Fruit and vegetable consumption is growing rapidly in recent years (Schirra et al., 2011). Associated with the new consumer's profile "rich in cash/poor in time", there is a demand for ready-to-eat products. For this reason, the market of minimally processed fruits has grown rapidly in recent decades, as a result of changes in consumer attitudes (Xu et al., 2011). On the other hand, the market of fruit diseases, disorders and insect infestations require a high level of effective pest control, which, despite the important achievements of modern agriculture, is still heavily dependent on synthetic agrochemicals. It is estimated that about $20-25 \%$ of the harvested fruits and vegetables are decayed by pathogens during postharvest handling even in developed countries (Droby, 2005). Over the past 15 years, biological control has emerged as an effective strategy to combat major postharvest decays of fruits. Effective use of biological control is a potentially important component of sustainable agriculture. The principal biocontrol mechanisms include mycoparasitism, antibiosis, competition and induced resistance. Nevertheless, application of antagonistic microorganisms alone does not provide commercially acceptable control of postharvest diseases (Spadaro and Gullino, 2004). In order to substitute synthetic fungicides, more environmentally friendly and harmless compounds should be developed as alternative methods for postharvest diseases (Droby et al., 2003).

The Chinese chestnut (Castanea mollissima Blume) is popular in East and Southeast Asia because of its sweet taste. However, browning and postharvest diseases are serious technical problems in chestnut processing (Zhou et al., 2015). This cause enormous economic loss in Asia. In recent years, several studies on biological control focused largely on Trichoderma asperellum, Pseudomonas fluorescens, Bacillus subtilis as antagonistic bacteria (Mbarga et al., 2014; Schmidt 
160

et al., 2004). Few trials reported the preparation of endophytic bacteria wettable powder for biological control of postharvest diseases. The present study was formulated with the following objectives: firstly, to evaluate the bio-efficacy of the water in wettable powder formulation of CE3 strain under field and postharvest conditions; secondly, to study the activity of defense related enzymes under field and postharvest conditions.

Results obtained from previous work have indicated that the control effect on main diseases of harvested chestnut could reach more than $70 \%$ using Bacillus cereus CE3 combined with auxiliary adjuvants. However, preliminary processing is necessary if its application field is extended. Nowadays, the major formulations include liquid agent, granules, wettable powder, wherein the wettable powder can be diluted into aqueous suspensions which are convenient for immersion or spraying treatment. Thus, it is widely used in disease prevention due to which it can be relative easy to associate, contains no organic solvent, and is convenient to store and transport. Wettable powder includes mica powder, carrier, wetting agent, dispersing agent, stabilizer and protective agent etc. In this work, screening experiments were conducted to investigate the biocompatibility of such additives and $B$. cereus $\mathrm{CE} 3$. The finding of this study will help to optimize the practical use of Bacillus cereus wettable powder in the biological control of fruit rot caused by Endothia parasitica (Murr), Fusarium solani.

\section{Materials and methods}

\section{Bacterium strain}

The CE3 (a type of Bacillus cereus Frankland) was isolated from the inside of chestnut fruits using method of Hua (2014) and identified by morphological, physiological experiments and ITS gene analysis.

\section{The chestnutseeds}

The cultivars 'Bayuehong' and 'Wukeli' of chestnuts were collected in this experiment. The chestnut were selected free of pests, diseases and wounds, as picked from Luotian (east longitude $115^{\circ} 26^{\prime}$, northern latitude $30^{\circ} 37^{\prime}$ ) Hubei province, China.

\section{Reagents}

Carrier: bentonite, silica, light calcium carbonate, kaolin, diatomite; Wetting agent: tea saponin, sodium dodecyl sulfate (SDS), sodium dodecyl benzene sulfonate (SDB-Na), naphthalene sulfonate (Morwet EFW); Dispersant: sodium lignin sulfonate, D-425, polyvinyl alcohol (PVA), calgon, sodium carboxymethyl cellulose (CMC-Na); Stabilizer: $\mathrm{CaCO}_{3}$, xanthan gum, $\mathrm{K}_{2} \mathrm{HPO}_{4}$; UV protective agent: VC (ascorbic acid) as the CMC (carboxymethyl cellulose), $\beta$ cyclodextrin; $70 \%$ thiophanate methyl wettable powder purchased in Shouguang Gardening Co. Ltd (Shandong, China).

\section{Preparation offreeze-drying Bacillus cereus CE3 micapowder}

B. cereus $\mathrm{CE} 3$ was selected and inoculated into $50 \mathrm{~mL} \mathrm{LB}$ liquid culture medium, cultivated at $30{ }^{\circ} \mathrm{C}, 180 \mathrm{rpm}$. After activation, it was transferred to the $100 \mathrm{~mL}$ fermentation medium with the inoculation amount of $2 \%$ and was cultivated for $48 \mathrm{~h}$ at the temperature of $30^{\circ} \mathrm{C}$ and the vibration frequency of $180 \mathrm{rpm}$. After $5 \%$ cryoprotectants was added, the fermentation liquid was placed in an ultra low temperature freezer, at $-80^{\circ} \mathrm{C}$ for $3 \mathrm{~h}$ and then it was moved into the freezing dryer, for freeze-drying. The temperature of the freeze dryer was set for $-60^{\circ} \mathrm{C}$, the vacuum for $100 \mathrm{~Pa}$ and the freeze-drying time for $24 \mathrm{~h}$. The freeze-drying Bacillus cereus CE3 mica powder obtained in this process was stored at $4^{\circ} \mathrm{C}$.

\section{Composition of the preliminary formulation}

The composition of the preliminary formulation was: $60 \%$ freeze-drying original powder, 10\% additives (including 5\% wetting agent and $5 \%$ dispersant), $1 \%$ stabilizer, $0.1 \%$ protective agent and complement to $100 \%$ with carrier material.

\section{Screening of the carrier}

Five types of carriers (silica aerogel, $\mathrm{CaCO}_{3}$, diatomite, bentonite, kaolin) were selected and mixed with the freeze-drying B. cereus $\mathrm{CE} 3$ original powder according to the ratio of the preliminary formulation. After 14 days storage at room temperature, the cell survival rate in each formulation was measured in order to investigate the biocompatibility of the carriers and B. cereus CE3. The optimum carrier was selected by systematically considering many factors, such as suspension rate and price.

Screening of dispersant and wetting agent as well as determination of their amounts

According to the initial ratio, 5\% wetting agent and 5\% dispersant was added to the original powder with carrier and then mixed uniformly. Then the suspension rate and wetting time of each formulation was measured. Generally, the higher suspension rate, the better its dispersion; the shorter wetting time, the better wettability. The optimal wetting agent and the best dispersant were screened.

The dispersant and wetting agent selected from the additives were mixed with their mass ratio of 1:9, 2:8, 3:7, 4:6, 5:5, 6:4, 7:3, $8: 2$, 9:1, respectively. The optimum ratio was selected by measuring the suspension rate and wetting time.

\section{Screening of stabilizer and ultraviolet protective agent}

Using the screened dispersant, wetting agent and carrier, three stabilizers $\left(\mathrm{CaCO}_{3}\right.$, xanthan gum, $\left.\mathrm{K}_{2} \mathrm{HPO}_{4}\right)$ were added to the initial agent with the amount of $1 \%$, and mixed, respectively. After 14 days storage at $54^{\circ} \mathrm{C}$, the cell concentration and suspension rate of each formulation were determined and the one without stabilizer was used as control. Subsequently, the best stabilizer was selected for final formulation.

Using the screened stabilizer, additives and carrier, $0.1 \%$ UV protective agent was added to the initial agent. After being diluted, they were coated on the plate placed in the positions which were of $30 \mathrm{~cm}$ away from the UV light $(254 \mathrm{~nm}, 20 \mathrm{~W})$, exposing for $24 \mathrm{~h}$ and $48 \mathrm{~h}$, respectively. The best UV protective agent was selected by measuring the survival rate. The agent without protection served as control.

\section{Determination of moisture content and suspension rate}

The moisture content was determined via drying constant weight method according to the national pesticide wettable powder wetting time determination standard GB/T 1600-01. 
According to the national pesticide wettable powder suspension rate determination standard GB/T 14825-93, 1 g samples were accurately weighted and added into an open bottle with plug with $50 \mathrm{~mL}$ standard hard water, which was vibrated at $120 \mathrm{r} / \mathrm{min}$ for $2 \mathrm{~min}$ so that it could be uniformly dispersed; then it was kept in $30^{\circ} \mathrm{C}$ water bath for $13 \mathrm{~min}$, after which it was diluted to $250 \mathrm{~mL}$ with standard hard water at $30^{\circ} \mathrm{C}$; following, the plug was kept on. The cylinder was overturned (kept upside and down) 30 times within $1 \mathrm{~min}$ and the plug was removed. The bottle was positioned vertically in a constant temperature water bath, standing for $30 \mathrm{~min}$. $9 / 10$ of the upper suspension aspiration was transferred with straw in $10-15$ seconds, the remaining $1 / 10$ was completely removed and transferred to a beaker. The beaker was kept in an oven with the temperature of $54^{\circ} \mathrm{C}$, drying to constant weight.

The suspension rate $(\mathrm{X})$ was calculated according to the formula:

$$
\mathrm{X}=\left(\mathrm{m}_{1}-\mathrm{m}_{2}\right) / \mathrm{m}_{1} \times 10 / 9 \times 100 \%
$$

Where, $\mathrm{m}_{\mathrm{I}}$ is the quality of the sample $(\mathrm{g})$; $\mathrm{m}_{2}$ is the quality of the $1 / 10$ residue $(\mathrm{g})$.

\section{Determination of wetting time and fineness degree}

According to the Chinese pesticide wettable powder wetting time determination standard GB/T 5451-01, $100 \mathrm{~mL}$ standard hard water were put into a $250 \mathrm{~mL}$ beaker, then it was placed in the water bath with a constant temperature of $25^{\circ} \mathrm{C}$, where the liquid surface of the sample and surface of the water bath were at the same level. When the temperature of the hard water also reached $25^{\circ} \mathrm{C}, 1 \mathrm{~g}$ of the sample was weighted and putted into the breaker in the flush position quickly. The liquid surface was kept static, with no disturbance. The time was measured immediately after removing the sample.

The wetting times of all the samples were noted. The experiments were repeated for 3 times and the wetting time was recorded as the average value.

According to the national pesticide wettable powder fineness determination standard GB/T16150-95, the samples were placed in the oven and dried to the constant weight and natural cooled to room temperature. When its humidity was the same as that of the atmosphere, it was weighted and screened with a sieve of 325 mesh. The residue in the sieve was weighted to calculate of fineness:

$$
\mathrm{F}=\left(\mathrm{m}_{1}-\mathrm{m}_{2}\right) / \mathrm{m}_{1} \times 100 \%
$$

Where: $\mathrm{m}_{\mathrm{l}}$ denotes the quality of the powder sample $(\mathrm{g}) ; \mathrm{m}_{2}$ denotes the quality of the residue (g).

\section{Wettable toxicity measurements}

Adult healthy SD rats with the weight in the range of 180-220 $\mathrm{g}$, half male and half female, were selected to conduct these experiments, where four individual mass dose groups were used: 5 , 50,500 and $5,000 \mathrm{mg} / \mathrm{kg}$, respectively. Each dose group contained 20 rats, half male and half female, which obtained the agent by oral administration. Their poisoning symptoms and death rate were observed with the period of 10 days. LD50 was obtained by Karber's method to classify the toxicity grade.

The formula used was: $\mathrm{m}=\mathrm{X}_{\mathrm{k}} \mathrm{i}\left(\sum \mathrm{p}-0.5\right)$

Where:

$\mathrm{X}_{\mathrm{k}}$ : the maximum dose of the numerical value; $\sum \mathrm{p}$ : the sum of mortality in each dose group;

I: the numerical difference of two adjacent groups;

LD50: median lethal dose.

\section{Controlexperiments}

The experiments consisted of 6 treatments: (1) preparation of $60 \%$ B. cereus wettable powder solution of 100, 500, 1,000 fold, respectively; (2) using $70 \%$ thiophanate methyl wettable powder solution of 100, 500, 1,000 fold, respectively; (3) normal water as control. Chestnuts without disease or bug eye were selected for the experiments on which the formulations were sprayed (in the form of fog, but not droplet). The samples were stored at $25^{\circ} \mathrm{C}$ for 30 days. Then the chestnuts were cut off to conduct the morbidity statistics. For each treatment group, there were 60 chestnuts and each experiment was repeated for three times.

\section{Statistical analysis}

The data were analyzed by the analysis of the variance (ANOVA) in SPSS. Mean were separated by Tukeys HSD at $\mathrm{P}<0.05$.

\section{Results}

\section{Screening of the carrier for CE3}

There was a direct influence on the performance of the formulation with different carriers selected. As shown in Table 1, the formulation with bentonite had a maximum suspension rate compared to the other treatment. The formulation with diatomite was the second. However, the cell survival rate was lower for the sample mixed with bentonite that was stored at room temperature for 14 days, which indicated a poor biological compatibility between bentonite and Bacillus cereus CE3. In addition, bentonite has a higher cost compared to diatomite. Thus, it was a suitable selection to take diatomite as the formulation carrier in considering biocompatibility, suspension rate and price.

Table 1. Influences on agent physicochemical properties with five carriers

\begin{tabular}{lccc}
\hline Packing material & $\begin{array}{c}\text { Suspension } \\
\text { percentage } \\
(\%)\end{array}$ & $\begin{array}{c}\text { Survival rate } \\
(\%)\end{array}$ & $\begin{array}{c}\text { Granularity } \\
(\leqq 45 \mu \mathrm{m} \%)\end{array}$ \\
\hline Bentonite & 82.13 & 62.61 & 100 \\
White Carbon Black & 74.28 & 74.23 & 100 \\
$\begin{array}{l}\text { Light Calcium } \\
\text { Carbonate }\end{array}$ & 75.23 & 73.12 & 98 \\
Diatomite & 79.47 & 86.93 & 100
\end{tabular}

\section{Screening of additives and dosages}

Some wettable agents also have dispersion effect, while some dispersants are also wettable, therefore the suspension rate and wetting time were considered for dispersant and wetting agent screening. It was observed that the 5 types of dispersants influenced the physicochemical properties of the agent (Table 2). Although the highest suspension rate $(86.49 \%)$ was obtained when D- 425 served as dispersant, it had a poor wettability time of $102.36 \mathrm{~s}$. In contrast, the suspension rate decreased by $5.85 \%$ when sodium lingosulfonate served as dispersant, in wetting time of $72.51 \mathrm{~s}$, and cell content was also higher in this treatment. Thus, sodium lignosulfonate was selected as dispersant of the agent. 
162

Table 2. Influences on agent physicochemical properties with different dispersant

\begin{tabular}{lccc}
\hline Disperser & $\begin{array}{c}\text { Suspension } \\
\text { percentage } \\
(\%)\end{array}$ & $\begin{array}{c}\text { Wetting } \\
\text { time }(\mathrm{s})\end{array}$ & $\begin{array}{c}\text { The content of } \\
\text { bacteria } \\
\left(10^{9} \mathrm{cfu} / \mathrm{g}\right)\end{array}$ \\
\hline $\begin{array}{l}\text { Sodium lignin } \\
\text { sulfonate }\end{array}$ & 80.64 & 72.51 & 2.30 \\
$\begin{array}{l}\text { Polyving akohol, } \\
\text { PVA }\end{array}$ & 68.23 & 83.45 & 1.95 \\
$\begin{array}{l}\text { Sodium alkyl } \\
\text { naphthalene sulfonic } \\
\text { acid condensation } \\
\text { polymer salt, D-425 }\end{array}$ & 86.49 & 102.36 & 2.15 \\
$\begin{array}{l}\text { Sodium } \\
\text { hexametaphosphate }\end{array}$ & 70.43 & 86.80 & 2.10 \\
$\begin{array}{l}\text { Sodium } \\
\text { carboxymethylcellul } \\
\text { ose, CMC-Na }\end{array}$ & 62.99 & 73.28 & 2.25 \\
\hline
\end{tabular}

The 4 types of wetting agent had a prominent influence on the physicochemical properties of the agents (Table 3). Morwet EFW had the highest suspension rate, $82.44 \%$, and it also had the shortest wetting time, only 68.37 s. So, the data suggested that Morwet EFW can be selected as wetting agent. Based on the results, it was suitable to select sodium lignosulfonate as a dispersant and Morwet EFW as a wetting agent for the formulation study.

To obtain optimum proportion, the mixture agent contents of sodium lignosulfonate and Morwet EFW were screened and data are summarized on Table 4 . The results indicated that the suspension rate and the wetting time increased when the proportion of the dispersant improved. As their mass ratio was 4:6, the wetting time could be controlled within $1 \mathrm{~min}$ and the suspension rate could be above $80 \%$, which could meet the quality control specifications. So, it suggested that the ratio of sodium lignosulfonate and Morwet EFW could be selected to be 4:6.

Table 3. Influences on agent physicochemical properties with wetting agents

\begin{tabular}{lccc}
\hline Wetting agent & $\begin{array}{c}\text { Suspension } \\
\text { percentage }(\%)\end{array}$ & $\begin{array}{c}\text { Wetting time } \\
(\mathrm{s})\end{array}$ & $\begin{array}{c}\text { The content of } \\
\text { bacteria } \\
\left(10^{\circ} \mathrm{cfu} / \mathrm{g}\right)\end{array}$ \\
\hline SDS & 70.28 & 72.54 & 2.47 \\
Morwet EFW & 82.44 & 68.37 & 2.47 \\
Tea saponin & 76.35 & 78.25 & 2.31 \\
DBS-Na & 65.13 & 75.29 & 2.39 \\
\hline
\end{tabular}

Table 4. Selecting the optimum proportion of sodium lignin sulphonate and Morwet EFW

\begin{tabular}{lcc}
\hline Proportion & $\begin{array}{c}\text { Suspension percentage } \\
(\%)\end{array}$ & $\begin{array}{c}\text { Wetting time } \\
(\mathrm{s})\end{array}$ \\
\hline $1: 9$ & 68.47 & 37.34 \\
$2: 8$ & 72.35 & 39.75 \\
$3: 7$ & 79.23 & 43.82 \\
$4: 6$ & 81.69 & 50.17 \\
$5: 5$ & 84.25 & 62.42 \\
$6: 4$ & 86.37 & 68.57 \\
$7: 3$ & 89.42 & 74.55 \\
$8: 2$ & 92.55 & 80.36 \\
$9: 1$ & 95.78 & 93.44 \\
\hline
\end{tabular}

\section{Screening of stabilizer}

Stabilizer can not only suppress the decomposition of active components during the storage of wetting powder, but also can enhance its viscosity and prevent sedimentation. Three different stabilizers were selected and their influence on the physicochemical properties of the formulation was conducted after storing at $54^{\circ}$ for 14 days (Table 5). Compared with the control, in the presence of $\mathrm{K}_{2} \mathrm{HPO}_{4}$, the bacterial decomposition rate within the formulation was dropped to below $5 \%$, indicating that $\mathrm{K}_{2} \mathrm{HPO}_{4}$ could significantly reduce the thermal decomposition of $B$. cereus in the storage environment. At the same time, the suspension rate and wetting time were not influenced, which could still meet the quality control specifications. Thus, it was right to select $\mathrm{K}_{2} \mathrm{HPO}_{4}$ as the stabilizer of the formulation.

Table 5. Influences on agent physicochemical properties with a stabilizer

\begin{tabular}{lccc}
\hline Stabilizer & $\begin{array}{c}\text { Decomposition } \\
\text { rate }(\%)\end{array}$ & $\begin{array}{c}\text { Suspension percentage } \\
(\%)\end{array}$ & $\begin{array}{c}\text { Wetting time } \\
(\mathrm{s})\end{array}$ \\
\hline $\mathrm{CaCO}_{3}$ & 6.14 & 75.29 & 67.48 \\
$\mathrm{Xanthan}_{3}$ gum & 10.03 & 64.36 & 71.29 \\
$\mathrm{~K}_{2} \mathrm{HPO}_{4}$ & 4.87 & 82.23 & 56.21 \\
$\mathrm{CK}$ & 28.52 & 51.47 & 150.15 \\
\hline
\end{tabular}

\section{Screening of UV protective agent}

In the future, considering the application in the wild environment, ultraviolet light would threaten or withhold the growth of $B$. cereus $\mathrm{CE} 3$; therefore, it is necessary to add UV protective agent and the screening of UV protective agent in the wettable powder formulation. It can be seen from Table 6 data, that with $\beta$-cyclodextrin as UV protective agent, the bacterial decomposition rate was the lowest after ultraviolet irradiation treatment for $24 \mathrm{~h}$ and $48 \mathrm{~h}$ respectively. Thus, it was appropriate to use $\beta$-cyclodextrin as the UV protective agent. However, further improvement also needs to be done if the formulation is to be extended to the wild environment.

Table 6. Influences on agent physicochemical properties with UV protection agents

\begin{tabular}{|c|c|c|c|c|c|}
\hline \multirow{2}{*}{$\begin{array}{l}\text { Protective } \\
\text { agent }\end{array}$} & \multirow{2}{*}{$\begin{array}{c}\text { Bacteria } \\
\text { content } \\
\text { beforeUV } \\
\text { irradiation } \\
/\left(10^{9} \mathrm{cu} / \mathrm{g}\right)\end{array}$} & \multicolumn{2}{|c|}{ UVtrearmentfor $24 \mathrm{~h}$} & \multicolumn{2}{|c|}{ UVtrearment $48 \mathrm{~h}$} \\
\hline & & $\begin{array}{l}\text { Bacteria } \\
/\left(10^{9}\right. \\
\text { fu/g })\end{array}$ & $\begin{array}{c}\text { Decomposition } \\
\text { rate } \\
(\%)\end{array}$ & $\begin{array}{c}\text { Bacteria } \\
/\left(10^{9}\right. \\
\mathrm{cu} / \mathrm{g})\end{array}$ & $\begin{array}{l}\text { Decomposition } \\
\text { rate(\%) }\end{array}$ \\
\hline $\mathrm{VC}$ & 2.47 & 1.77 & 28.48 & 1.16 & 52.94 \\
\hline $\mathrm{CMC}$ & 2.47 & 1.96 & 20.57 & 1.27 & 48.57 \\
\hline $\begin{array}{l}\beta- \\
\text { cyclodextrin }\end{array}$ & 2.47 & 2.17 & 12.17 & 2.09 & 15.28 \\
\hline CK & 2.47 & 1.45 & 41.13 & 0.95 & 61.73 \\
\hline
\end{tabular}

\section{Wettablepowder related indexes and safety evaluation}

According to the screening experiments for the carrier additives of $B$. cereus wettable powder, it was determined that the optimum formulation contained 60\% fungus powder, $28.9 \%$ diatomite, $4 \%$ sodium lignin sulfonate, $6 \% \mathrm{EFW}, 1 \% \mathrm{~K}_{2} \mathrm{HPO}_{4}$, $0.1 \% \beta$-cyclodextrin. The quality indexes of the products were measured. The results showed that the indexes of the formulation was Lactobacillus content $2.46 \times 109 \mathrm{CFU} / \mathrm{g}, \mathrm{pH}$ value 7.6 , moisture content $2 \%$, suspension rate $82.27 \%$, wetting for $51.43 \mathrm{~s}$, fineness $99.3 \%$ passing 325 mesh sieve (Fig. 1). All the parameters conform to the quality requirements of pesticide wettable powder. 


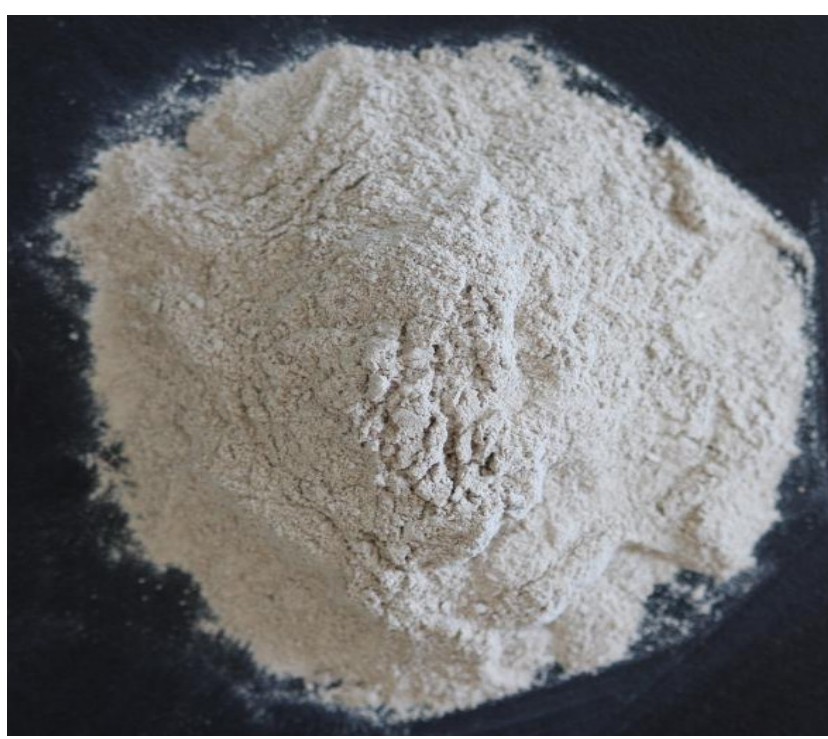

Fig. 1. Bacillus cereus wettable powder

Biological safety is the premise of the industrialization of microbial pesticides. The oral toxicology test of $B$. cereus wettable powder (Table 7) showed that the acute oral LD50 for male and female SD (Sprague Dawley) rats was 5,000.35, which was higher than $5,000 \mathrm{mg} / \mathrm{kg}$. According to the classification of acute toxicity of pesticides in China, it belongs to the low toxicity category, namely, slightly toxic class. Therefore, application of $B$. cereus wettable powder could not cause a person or animal poisoning, which was promising for application in the field and the wild environment.

\section{Control efficacy test}

As shown in Table 8, after 30 days of treatment, the disease control effect of $60 \%$ B. cereus wettable powder solution of 100 fold on harvested chestnut reached $79.47 \%$, which was equal to the commercial available and commonly used effective chemical bactericide, the $70 \%$ thiophanate methyl of wetting powder solution of 1,000 fold. In the level of $\mathrm{P}=0.05$, there were no significant differences. Thus, $60 \% \mathrm{~B}$. cereus wettable powder solution of 100 fold can be used for prevention and control of harvested chestnut diseases.

Table 7 . The death rate of rats after toxicity experiment

\begin{tabular}{lcccccc}
\hline Group & Dosage $(\mathrm{mg} / \mathrm{kg})$ & $\begin{array}{c}\text { No. of } \\
\text { animal }\end{array}$ & Dead & $\begin{array}{c}\text { Death } \\
\text { rate }\end{array}$ & $\begin{array}{c}\text { Survival } \\
\text { rate }\end{array}$ \\
\hline 1 & 5 & 0.6990 & 20 & 0 & 0 & 1 \\
2 & 50 & 1.6990 & 20 & 0 & 0 & 1 \\
3 & 500 & 2.6990 & 20 & 0 & 0 & 1 \\
4 & 5000 & 3.6990 & 20 & 1 & 0.05 & 0.95 \\
\hline
\end{tabular}

Table 8 . The preventing and controlling effects on chestnut propagate with wettable powder of $B$. cereus

\begin{tabular}{lcc}
\hline \multicolumn{1}{c}{ Treatments } & Dilution ratio & Morbidity (\%) \\
\hline & 100 & $20.53 \pm 0.92 \mathrm{~d}$ \\
60\% of wettable powder of & 500 & $40.53 \pm 4.22 \mathrm{c}$ \\
B. cereus & 1000 & $79.96 \pm 6.65 \mathrm{~b}$ \\
70\% wettable powder of & 100 & $6.07 \pm 0.92 \mathrm{e}$ \\
thiophanate methyl & 500 & $9.43 \pm 4.17 \mathrm{e}$ \\
CK & 1000 & $18.87 \pm 0.98 \mathrm{~d}$ \\
\hline
\end{tabular}

\section{Discussions}

As an important measure to development low toxicity, green agriculture is using antagonists to serve as biocontrol pesticide (Mbarga et al., 2014; Quaglia et al., 2011). Previously, biocontrol pesticide formulation was used in the form of water or oil base agentia, however, it is inconvenient for the transport and storage (Mbarga et al., 2014; Yánez et al., 2012). Wettable powder, the main form of biocontrol pesticide, fundamentally overcomes the disadvantages of the liquid agent, furthermore, its resistance to outside interference enhances and its performance becomes more stable (Bora et al., 2004). Thus, the screened ingredients were prepared as $60 \% \mathrm{~B}$. cereus CE3 wettable powder and the content of the formulation was: $60 \%$ bacteria powder, $28.9 \%$ diatomite, $4 \%$ lignosulfonate, $6 \% \mathrm{EFW}, 1 \% \mathrm{~K}_{2} \mathrm{HPO}_{4}, 0.1 \%$ $\beta$-cyclodextrin. Their performance indexes were: $\mathrm{pH}$ value 7.6 , moisture content $2 \%$, suspension rate $82.27 \%$, wetting time $51.43 \mathrm{~s}, 99.3 \%$ passing the 325 mesh sieve. All the indicators conform to the quality requirements of pesticide wettable powder in China, which would provide a basis for the investigation of actual formulations.

A primary prevention study was conducted on $B$. cereus CE3 laboratory sample. The control tests showed that the disease control effect of $60 \%$ CE3 wettable powder solution of 100 fold on harvested chestnut reached $79.47 \%$, which was equal to commercially available and commonly used effective chemical bactericide, the $70 \%$ thiophanate methyl of wettable powder solution of 1,000 fold. Thus, it is recommended to use $60 \%$ CE3 wettable powder solution of 100 fold for main diseases prevention of harvested chestnut. However, masses production processes needs to be further studied. In addition, due to the limited time, this experiment did not include the investigation of synergistic factor of wettable powder, and assistants, additives and their amounts screening were not using the orthogonal experiment; instead, it referred to the work of Wen (2013), using 60\% freeze-drying original powder, $10 \%$ assistants, $20 \%$ carrier, $1 \%$ stabilizer and $0.1 \%$ protective agent as the initial content of the primary formulation. In addition, during the screening of auxiliary agent such as additives, the types used were limited.

\section{Conclusions}

Never the less, for the final formulation, from lab achievement to commercial production, there are still many aspects that need to be solved. Firstly, the cost of fermentation culture of $B$. cereus $\mathrm{CE} 3$ should be controlled to a lower level. Secondly, it needs to be explored which types of active components can perform preservation effect and how to store the active components. Thirdly, the formulation of wettable powder needs to be optimized, and the measures of increasing efficiency explored. Anyhow, the present study is promising and data could be used to obtain an improved, more stable product, of $B$. cereus $\mathrm{CE} 3$, for the application at the biological control of chestnut and other fruit in commercial field.

\section{Acknowledgements}

This work was supported by the Foundation for Innovative Research Group of Natural Science of Hubei Province (2010CBB03901), the Science Research Fund of Hubei Educational Office (Q20132909). 
164

\section{References}

Bora T, Özaktan H, Göre E, Aslan E (2004). Biological control of Fusarium oxysporum $\mathrm{f}$. sp. melonis by wettable powder formulations of the two strains of Pseudomonas putida. J Phytopathol 152(8):471-475.

Droby S (2005). Improving quality and safety of fresh fruits and vegetables after harvest by the use of biocontrol agents and natural materials. 1st International Symposium on Natural Preservatives in Food Systems 709:45-52.

Droby S, Wisniewski M, El Ghaouth A, Wilson C (2003). Influence of food additives on the control of postharvest rots of apple and peach and efficacy of the yeast-based biocontrol product Aspire. Postharvest Biol Tec 27(2):127-135.

Hua J (2014). Study on screening, identification of postharvest pathogens of chestnut and the antiseptic technique. Wuhan Institute of Technology, Hubei Wuhan China, Master. Chapter 3, pp 33-45.

Mbarga J, Begoude B, Ambang Z, Meboma M, Kuate J, Schiffers B, Ewbank W, Dedieu L, Ten HG (2014). A new oil-based formulation of Trichoderma asperellum for the biological control of cacao black pod disease caused by Phytophthora megakarya. Biol Control 77:15-22.

Quaglia M, Ederli L, Pasqualini S, Zazzerini A (2011). Biological control agents and chemical inducers of resistance for postharvest control of Penicillium expansum on apple fruit. Postharvest Biol Tec 59(3):307-315.
Schirra M, D’Aquino S, Cabras P, Angioni A (2011). Control of postharvest diseases of fruit by heat and fungicides: efficacy, residue levels, and residue persistence. A review. J Agr Food Chem 59(16):8531-8542.

Schmidt C, Agostini F, Leifert C, Killham K, Mullins C (2004). Influence of soil temperature and matric potential on sugar beet seedling colonization and suppression of Pythium damping-off by the antagonistic bacteria Pseudomonas fluorescens and Bacillus subtilis. Phytopathology 94(4):351-363.

Spadaro D, Gullino ML (2004). State of the art and future prospects of the biological control of postharvest fruit diseases. Int J Food Microbiol 91(2):185-194.

Wen X (2013). Cloning of chitinase gene and development of wettable powders from Xenorhabdus nematophila HB310 strain. Agricultural University of Hebei, Shijiazhuang Hebei China, Master Thesis Abstr 12-26.

Xu X-M, Jeffries P, Pautasso M, Jeger M (2011). Combined use of biocontrol agents to manage plant diseases in theory and practice. Phytopathology 101(9):1024-1031.

Yánez MV, Viñas I, Usall J, Torres R, Solsona C, Abadias M, Teixido N (2012). Formulation development of the biocontrol agent Bacillus subtilis strain CPA-8 by spray-drying. J Appl Microbiol 112(5):954 965.

Zhou D, Li L, Wu Y, Fan J, Ouyang J (2015). Salicylic acid inhibits enzymatic browning of fresh-cut Chinese chestnut (Castanea mollissima) by competitively inhibiting polyphenol oxidase. Food Chem 171(15):19-25. 